\title{
Kreativitas Influencer dalam Mengampanyekan Self Love untuk Kesehatan Mental di Instagram
}

\author{
Vonny Felicia Hastan ${ }^{1}$, Gregorius Genep Sukendro ${ }^{2 *}$ \\ ${ }^{1}$ Fakultas Ilmu Komunikasi, Universitas Tarumanagara, Jakarta \\ Email:vonnyfelicia@gmail.com \\ ${ }^{2}$ Fakultas Ilmu Komunikasi, Universitas Tarumanagara, Jakarta* \\ Email: geneps@fikom.untar.ac.id
}

Masuk tanggal : 15-12-2021, revisi tanggal : 06-01-2022, diterima untuk diterbitkan tanggal : 16-01-2022

\begin{abstract}
Self love is often seen as something that is easily owned and felt by everyone. In fact, there are still many individuals who feel the impact of the absence of self love, such as depression, anti socialism, loneliness, excessive anxiety, et cetera. These impacts are often referred as mental health disorders. Meanwhile, in this modern era, almost everyone has 'Instagram' social media. Through Instagram, we can exchange information, upload photos or videos, communicate, and promote stuff and services. However, through Instagram, an individual can also become depressed because she/he often sees other people whose considered better than themselves. Therefore, an influencer named Khalisa Cantara Ramadhany who has the ability to persuade other people because of her large number of followers on Instagram has started to open her voice and created creative campaign about self love to help broaden people's perspective and to help eliminating the factors that causing someone to not love themselves. For example is an unreasonable beauty standard. Other factors that can influence self love are self esteem, self confidence, and self expression or how we express ourselves.
\end{abstract}

Keywords: creative campaign, influencer, Instagram social media, mental health, self love

\begin{abstract}
Abstrak
Di era modern ini hampir semua orang mempunyai media sosial Instagram. Melalui Instagram, kita dapat bertukar informasi, mengunggah foto maupun video, dapat berkomunikasi, serta dapat mengampanyekan atau memasarkan barang dan jasa. Namun melalui media sosial Instagram juga seorang individu dapat menjadi depresi karena melihat orang lain yang dianggap lebih baik. Karena itu, seorang influencer bernama Khalisa Cantara Ramadhany yang memiliki kemampuan mempersuasi orang lain karena jumlah pengikutnya yang banyak di Instagram mulai membuka suara dan membuat kampanye kreatif mengenai self love untuk membantu memperluas pandangan masyarakat serta membantu menghilangkan faktor-faktor penyebab seseorang menjadi tidak cinta terhadap dirinya sendiri, contohnya standar kecantikan yang tidak masuk akal. Faktor-faktor lainnya yang dapat memengaruhi sikap mencintai diri sendiri adalah sikap menghargai diri sendiri, kepercayaan diri dan bagaimana kita mengekspresikan diri.
\end{abstract}

Kata Kunci: kampanye kreatif, kesehatan mental, media sosial Instagram, self love

\section{Pendahuluan}

Di era modern ini, teknologi berkembang semakin pesat dan dapat dibuktikan melalui media sosial yang terus bertambah setiap harinya. Chris Brogan (2010) dalam bukunya yang berjudul Social Media 101 Tactic and Tips to Develop 
Your Business Online mengartikan pengertian media sosial sebagai a new set of communication and collaboration tools that enable many types of interactions that were previously not available to the common person" atau lebih tepatnya media sosial adalah satu set baru komunikasi dan alat kolaborasi yang memungkinkan banyak jenis interaksi yang sebelumnya tidak tersedia untuk orang biasa. Hal yang terpenting dari teknologi ini adalah terjadinya pergeseran mengenai cara mengetahui orang lain, berbagi berita, serta mencari konten dan informasi. Terdapat banyak sekali saluran media sosial yang beroperasi di seluruh dunia saat ini, dengan tiga besar media sosial yang paling banyak digunakan diduduki oleh Facebook, LinkedIn dan Twitter (Badri, 2011).

Namun, selain tiga besar media sosial yang paling banyak digunakan menurut Badri (2011), media sosial Instagram juga berkembang semakin pesat. Instagram memberikan kemudahan akses bagi penggunanya untuk mencari dan berbagi konten dan informasi, serta berkomunikasi dengan sesama pengguna melalui fitur-fitur yang disediakan. Melalui kecanggihan dan kemudahan yang diberikan Instagram, pengguna Instagram terus bertambah setiap harinya dan masyarakat mulai melihat hal ini sebagai peluang untuk mencari uang tambahan, pekerjaan sampingan dan sebagai sarana untuk menjalankan kampanye untuk mengiklankan suatu barang atau jasa.

Beberapa orang yang menggunakan peluang ini dengan baik dan kreatif biasanya akan mendapat banyak pengikut dan disebut sebagai influencer karena kemampuannya untuk mempersuasi masyarakat untuk membeli barang atau jasa yang dipasarkan. Influencer menurut Brown \& Fiorella (2013:195) diartikan sebagai "Typically a noncustomer or business incentivized to recommend / create content about a business brand or product".

Dari pengertian tersebut dapat disimpulkan bahwa influencer adalah orang-orang yang memiliki jumlah pengikut atau audience yang cukup banyak di media sosial dan gemar mempromosikan suatu hal kepada calon pembeli. Banyaknya pengikut inilah yang menjadikan seorang influencer berpengaruh dalam mempromosikan atupun mengkampanyekan sesuatu, entah itu barang, jasa, atau bahkan isu.

Ketika seorang influencer memasarkan suatu produk, jasa atau pun informasi dan isu, audience akan menerima dan memproses bahkan terpengaruh untuk membeli barang yang diiklankan. Begitu pula dengan isu, isu yang dikampanye kan akan diterima sehingga melalui kampanye kreatif dan iklan di Instagram, pandangan masyarakat akan suatu isu dan topik akan menjadi lebih luas.

Isu yang sedang menjadi obrolan masyarakat di modern yang aktif menggunakan sosial media ini adalah isu-isu sosial seperti toxic masculinity, beauty standart, self love, dan masih banyak lagi. Namun peneliti ingin lebih fokus dalam membahas mengenai isu self love. Pada dasarnya, self love merupakan keadaan dimana seseorang merasa puas akan dirinya dan menerima kekurangannya.

Beberapa media seperti BBC News Indonesia bahkan sempat mengunggah artikel mengenai pentingnya kesehatan mental, seperti salah satu contoh artikel yang berjudul "Hari Kesehatan Jiwa Sedunia: Saya merasa benar-benar sendiri hingga sempat ingin bunuh diri". Selain itu, Kompas.com juga mengunggah artikel yang berjudul "Depresi dan Bunuh Diri di Indonesia diprediksi meningkat, mengapa?"

Melihat isu kesehatan mental dan dampaknya yang buruk bagi masyarakat yang semakin banyak setiap harinya, beberapa influencer di media sosial akhirnya melakukan gerakan atau kampanye pentingnya self love. Karena self love adalah 
salah satu faktor yang jika tidak dimiliki oleh seseorang, akan cenderung berdampak pada sakitnya mental dan jiwa nya.

Berdasarkan latar belakang yang peneliti paparkan diatas, rumusan masalah yang akan dibahas dalam penelitian ini adalah "Apa pentingnya self love bagi kesehatan mental seseorang?" Adapun tujuan dari penelitian ini adalah peneliti ingin mendalami pentingnya self love bagi kesehatan mental seseorang melalui kampanye kreatif di media sosial Instagram yang digerakan oleh para influencer.

\section{Metode Penelitian}

Pada penelitian ini peneliti menggunakan pendekatan deskriptif-kualitatif. Dalam buku yang berjudul Metodologi Penelitian Kualitatif, Lexy J. Moleong menjelaskan bahwa penelitian kualitatif merupakan penelitian yang bertujuan untuk memahami fenomena yang dialami oleh subjek penelitian misalnya perilaku, persepsi, motivasi dan tindakan secara holistik dengan cara deskripsi dalam bentuk kata-kata dan bahasa pada suatu konteks khusus yang alamiah dengan memanfaatkan berbagai metode alamiah (Moleong, 2009:6).

Dalam penelitian ini, peneliti sendiri berusaha untuk memahami fenomena yang dialami oleh subjek penelitian serta menghasilkan data deskriptif dari narasumber yang diteliti. Peneliti menggunakan pendekatan deskriptif-kualitatif karena menurut peneliti pendekatan ini adalah pendekatan yang paling sesuai dengan penelitian yang peneliti bahas.

Selain itu, peneliti juga menggunakan metode penelitian studi kasus. Deddy Mulyana dalam bukunya yang berjudul Metodologi Penelitian Kualitatif Paradigma Baru Ilmu Komunikasi dan Ilmu Sosial Lainnya, mengatakan bahwa metode penelitian studi kasus merupakan metode penelitian dimana sang peneliti berupaya menelaah data sebanyak mungkin tentang subjek yang diteliti. Metode yang biasa digunakan adalah wawancara, riwayat hidup, survei serta data yang terkait dengan kasus tersebut (Mulyana, 2001:201).

Dalam sebuah penelitian, subjek dan objek penelitian juga tentu merupakan aspek yang penting. Burhan Bungin dalam bukunya yang berjudul Penelitian Kualitatif: Komunikasi, Ekonomi, Kebijakan Publik dan Ilmu Sosial Lainnya berpendapat bahwa subyek penelitian adalah orang yang menjadi sumber informasi dan memahami obyek penelitian (Bungin, 2008:76). Sedangkan objek penelitian menurut Sugiyono dalam bukunya yang berjudul Metode Penelitian Kuantitatif, Kualitatif dan R\&D adalah situasi sosial yang terdiri atas tiga elemen yaitu tempat, pelaku dan aktivitas yang berinteraksi secara sinergis (Sugiyono, 2009:215).

Adapun subjek penelitian dalam penelitian ini adalah 4 orang narasumber, yaitu seorang key informan bernama Khalisha Cantara Ramadhany yang merupakan seorang influencer berusia 17 tahun yang aktif dalam kegiatan kampanye kreatif mengenai self love di media sosial Instagram, serta 3 orang narasumber lainnya yang memenuhi kriteria. Sedangkan, objek penelitian dalam penelitian ini adalah pentingnya kampanye self love beserta dengan faktor-faktor pendukungnya untuk kesehatan mental seseorang.

Sumber data yang digunakan dalam penelitian ini diperoleh dari wawancara . Wawancara, menurut Lexy J Moleong, adalah percakapan dengan maksud tertentu. Percakapan dilakukan oleh dua pihak yaitu pewawancara yang mengajukan pertanyaan dan orang yang diwawancarai yang memberikan jawaban (Moleong, 2009:186). 
Peneliti melakukan wawancara mendalam terhadap 4 orang narasumber yang memenuhi kriteria, yang merupakan subjek penelitian. Peneliti juga mendapatkan dokumentasi yang berupa segala bentuk data tertulis maupun tidak tertulis yang dapat menjadi data pendukung untuk penelitian ini. Selain itu, peneliti juga menggunakan metode pengumpulan data studi kepustakaan yang berupa buku, jurnal dan laporan penelitian yang sudah ada sebelumnya yang memiliki teori yang berhubungan sebagai pelengkap data untuk penelitian ini.

Peneliti mengolah dan menganalisa penelitian ini dengan melalui beberapa tahapan yaitu pengumpulan data, reduksi data, penyajian data dan pengambilan kesimpulan. Dalam bukunya yang berjudul Metode Penelitian Kualitatif karangan Lexy J. Moleong, proses analisis data dimulai dengan menelaah seluruh data yang tersedia dari berbagai sumber yaitu wawancara, pengamatan yang sudah dituliskan dalam catatan lapangan, dokumen pribadi, dokumen resmi, gambar, foto dan sebagainya (Moleong, 2009).

Tahapan pertama yang peneliti lakukan adalah pengumpulan data, yaitu peneliti mengumpulkan berbagai data yang diperlukan untuk membuat penelitian ini melalui wawancara mendalam dengan 4 orang narasumber, dokumentasi dan studi kepustakaan. Tahapan kedua adalah reduksi data, pada tahapan ini peneliti menyeleksi data yang peneliti dapatkan agar lebih jelas, tegas ringkas. Tahapan ketiga yang peneliti lakukan adalah penyajian data, peneliti menyajikan data yang sudah peneliti pertegas agar nantinya dapat ditarik kesimpulan dengan mudah. Tahapan keempat dan terakhir adalah penarikan kesimpulan, peneliti menyimpulkan data yang sudah peneliti pertegas dan sajikan dengan baik.

\section{Hasil Temuan dan Diskusi}

\section{Kreativitas Influencer Khalisa Cantara Ramadhany dalam Membangun Positivisme di Instagram}

Khalisa Cantara Ramadhany merupakan seorang influencer dengan jumlah pengikut 44.400 orang dan terus bertambah. Awal mula Khalisa menjadi seorang influencer adalah karena suatu kebetulan, dimana ia hanya melakukan apa yang ia suka, yaitu mengunggah dan membuka question box di Instagramnya mengenai topik-topik yang menurutnya penting dan sering dibicarakan di sekolahnya, namun tidak cukup dibicarakan di publik.

Namun, tanpa disadari semakin lama Khalisa menjadi semakin dikenal dan jumlah pengikutnya terus bertambah. Selain menjadi seorang influencer, Khalisa juga membuat clothing line bernama @selfworthfirst yang fokusnya adalah untuk memperluas pandangan masyarakat tentang positifisme tubuh, serta merupakan co-founder dan executive content writer unthuk @ arisearose, yaitu organisasi yang terbuka untuk saling berdiskusi mengenai suatu topik dan saling mendukung satu sama lain untuk menciptakan positivisme.

Selain itu, Khalisa juga membuat kampanye kreatif hashtag brave to be bare dan mengajak audience nya untuk mengunggah foto atau video diri mereka tanpa menggunakan riasan wajah serta mempersuasi masyarakat untuk percaya diri dan mencintai diri sendiri apa adanya.

\section{Cantik itu Luas dan Beragram}

Seperti yang sudah disebutkan sebelumnya, Khalisa adalah pribadi yang memiliki ketertarikan khusus pada topik dan isu tertentu seperti self love. Ia merasa 
bahwa banyak orang diluar sana yang tidak percaya diri dan tidak mencintai dirinya sendiri karena standar kecantikan di Indonesia yang tidak masuk akal yang secara tidak langsung mewajibkan perempuan untuk memiliki kulit yang bersih, putih, berambut panjang, memiliki tinggi dan berat badan yang pas, dan sebagainya untuk dianggap 'cantik'. Padahal, setiap manusia diciptakan cantik dan unik dengan caranya masing-masing.

Khalisa juga berpendapat bahwa sebagai manusia, kita tidak meminta untuk dilahirkan ingin seperti apa, karena itu kita tidak seharusnya diukur berdasarkan standar kecantikan yang tidak masuk akal. Khalisa juga mengekspresikan dirinya melalui photoshoot untuk clothing line milikinya @selfworthfirst dan melalui pembuatan kampanye kreatif hashtag brave to be bare. Ia menggunakan dirinya sendiri dan teman-temannya dengan bentuk tubuh dan warna kulit yang beragam. Ia bahkan sempat mengadakan photoshoot tanpa menggunakan riasan wajah untuk menunjukkan bahwa cantik tidak diukur melalui kondisi wajah kita.

Banyak orang di luar sana yang merasa tidak percaya diri karena kondisi wajahnya yang tidak baik, misalnya berjerawat. Padahal, jerawat adalah kondisi hormonal yang tidak bisa kita kontrol. Melalui kampanye kreatif hashtag brave to be bare, Khalisa seringkali mengunggah foto dirinya tanpa menggunakan riasan wajah dengan menunjukan segala kekurangan dan kondisi kulit yang dimilikinya. Ia juga mengunggah video di channel Youtube nya dan mengajak audience nya untuk mengunggah foto dan video diri mereka tanpa menggunakan riasan wajah dan menggunakan hashtag \#bravetobebare agar semakin banyak orang yang peduli akan isu ini serta menjadi percaya diri dan tidak merasa sendiri atas masalah apapun yang dihadapinya.

Selain dari pendapat Khalisa Cantara, ketiga informan lainnya yang peneliti wawancara juga memiliki pendapat yang kurang lebih sama, yakni standar kecantikan di Indonesia adalah hal yang tidak seharusnya ada dan tidak masuk akal karena cenderung menyebabkan banyak pihak merasa tidak percaya diri dan tidak dianggap karena tidak memenuhi "standar".

\section{Hubungan Gaya Hidup dan Self Love}

Gaya hidup juga merupakan salah satu faktor yang berhubungan dengan self love. Melalui Instagram, setiap orang diberikan kebebasan untuk mengunggah dan melihat unggahan orang lain mengenai kehidupan dan gaya hidupnya yang terkadang dianggap lebih baik. Hal ini cenderung menyebabkan seseorang menjadi merasa bahwa dirinya tidak cukup dan menjadi tidak cinta dan menghargai dirinya sendiri.

Menurut Khalisa sendiri, gaya hidup adalah hal yang relatif, namun masih banyak orang yang gaya hidupnya dipengaruhi oleh lingkungan sekitarnya. Tidak masalah jika ingin mengikuti gaya hidup orang lain karena kagum dan menjadikan orang tersebut sebagai inspirasi. Namun ada baiknya untuk menjaga keseimbangan antara keinginan dirinya sendiri serta pendapat dan kritik orang lain untuk saling membangun dan mendukung.

\section{Insecurities terhadap Sikap Self Love dan Konsep Diri}

Menurut Khalisa proses pembentukan konsep dan jati diri setiap orang itu berbeda-beda. Ada yang relatif lebih lama, ada pula yang relatif lebih cepat. Baginya, semua orang memiliki caranya masing-masing untuk menghadapi dan mengatasi insecurities nya dan semua kembali kepada diri orang itu masing-masing. Ada orang yang merasa insecure dan kemudian hal ini mempengaruhi jati dirinya namun ada 
pula orang yang merasa insecure namun tidak berpengaruh terhadap pembentukan konsep dirinya.

Namun, insecurities yang berlebihan tentu akan mempengaruhi karakteristik seseorang, yaitu menjadi selalu tidak puas akan dirinya sendiri dan tidak memiliki sikap self love, serta menjadi bingung dan tersesat akan keaslian atau jati diri nya sendiri. Namun, saat ditanya mengenai insecurities dalam wawancara mendalam melalui zoom pada tanggal 21 November 2020, Khalisa sendiri menjawab bahwa dirinya pun seringkali merasa insecure dan ia juga menambahkan bahwa tidak ada orang didunia ini yang tidak pernah merasa tidak insecure.

Ia berpendapat bahwa orang yang insecure sebenarnya adalah orang yang merasa bahwa dirinya bisa melakukan hal yang lebih, namun belum terlaksana atau mereka yang merasa dirinya memiliki kekurangan tertentu, namun belum bisa menghadapinya. Khalisa juga menambahkan bahwa alasan ia sering membuka dialog mengenai self love adalah karena ia seringkali merasa insecure namun ingin menghadapinya dan saling membantu agar banyak orang diluar sana yang tidak merasa sendiri.

\section{Kampanye Self Love}

Self esteem, self confidence, self expression, self worth, dan beauty standard adalah faktor yang secara tidak langsung mempengaruhi apakah seseorang memiliki sikap mencintai dirinya sendiri atau tidak. Dengan tidak adanya faktor-faktor tersebut, seorang individu akan cenderung merasa dirinya tidak pernah cukup serta merasa tidak pernah puas akan apa yang dimilikinya sekarang.

Melalui unggahan Khalisa menghapus riasan wajahnya di akun Instagramnya, Khalisa ingin menyampaikan pesan bahwa kepercayaan diri adalah salah satu hal yang sangat penting guna meningkatkan atau menimbulkan adanya sikap self love. Percaya diri akan wajahnya, tubuhnya dan berani mengekspresikan nya melalui akun Instagramnya, Khalisa berpendapat bahwa kita harus bisa mencintai diri kita apa adanya dengan kekurangan kita masing-masing.

Karena itulah melalui konten-kontennya, Khalisa selalu berusaha untuk mengampanyekan dan menyebarluaskan pentingnya percaya diri, mengapresiasi diri sendiri, dan yang terpenting adalah untuk mencintai diri kita sendiri dengan segala kekurangan yang dimiliki.

\section{Keberhasilan Kampanye Self Love}

Kampanye self love yang dikampanyekan oleh Khalisa di akun Instagram nya cukup menjangkau banyak audience, beberapa diantaranya adalah narasumber lainnya yang peneliti wawancara, yaitu Nada Wasisto, Audi Gracia dan Reinaldy Lie. Narasumber Nada Wasisto, Audi Gracia dan Reinaldy Lie pun setuju bahwa kampanye self love Khalisa sangat bermanfaat dan membantu dalam meningkatkan kepercayaan diri dan sikap self love. Mereka juga berpendapat bahwa kampanye self love Khalisa membuat pandangan dan perspektif dirinya akan standar kecantikan menjadi lebih luas.

\section{Pentingnya Self Love untuk Kesehatan Mental Individu}

Melalui wawancara mendalam, para narasumber pun memiliki pendapat yang kurang lebih sama bahwa faktor-faktor pendukung seperti self esteem, self confidence, self expression dan beauty standard sangat penting dalam pembentukan sikap mencintai dirinya sendiri bagi seorang individu. Tanpa adanya kepercayaan diri, 
seseorang akan cenderung selalu merasa insecure dan tidak percaya bahwa sebenarnya dirinya mampu untuk melakukan lebih. Tanpa ada nya self expression juga seseorang akan menjadi minder untuk mengekspresikan dirinya dan cenderung menjadi seseorang yang tidak kreatif dan menyendiri. Hal-hal ini akan menjurus kepada sikap tidak adanya rasa cinta atau pun sayang terhadap diri sendiri, yang akhirnya menimbulkan gangguan kesehatan mental seperti mudah marah, penyendiri, egois, tidak suka bergaul, kecemasan yang berlebihan dan depresi.

Narasumber dan peneliti setuju bahwa jika seseorang tidak memiliki sikap self love, individu akan cenderung merasakan terjadinya gangguan mental seperti depresi, anti sosial, penyendiri, gelisah, emosional, dan masih banyak lagi gangguan psikis lainnya. Karena itu, kampanye kreatif yang dilakukan oleh Khalisa Cantara Ramadhany selaku influencer di media sosial Instagram sangat penting dan bermanfaat untuk menjangkau lebih banyak lagi masyarakat agar lebih memahami dan peduli terhadap pentingnya self love untuk kesehatan mental individu.

\section{Simpulan}

Kesimpulan dari penelitian ini adalah bahwa dengan memanfaatkan media sosial Instagram di era modern ini, kampanye kreatif dan iklan dapat dipromosikan dan dipasarkan dengan cara yang mudah dan dapat pula menjangkau audience secara luas dengan tidak memerlukan biaya.

Melalui kampanye kreatif dan iklan, suatu produk, jasa dan isu atau berita akan dapat menyebar dengan mudahnya melalui pemasaran yang dilakukan oleh komunitas pengguna instagram yang aktif atau yang biasa disebut sebagai influencer.

Karena itu, seorang influencer bernama Khalisa Cantara Ramadhany melakukan pergerakan yaitu dengan membuat kampanye kreatif mengenai topik self love yang tujuannya untuk menjangkau lebih banyak lagi orang agar peduli dan percaya pada dirinya sendiri.

Kampanye kreatif yang dilakukan antara lain dengan menyebarkan kampanye hashtag brave to be bare melalui Instagram dan Youtube, dengan membuat clothing line bernama @selfworthfirst yang fokusnya agar masyarakat lebih peduli positifisme tubuh, dan menjadi Co-founder serta Executive Content Director untuk akun instagram @arisearose, yaitu organisasi yang aktif dan fokus dalam mengedukasi masyarakat terutama pengguna media sosial instagram untuk menyebarkan positivisme dengan tujuan membangun masyarakat Indonesia yang lebih baik.

Peneliti sebagai mahasiswi Ilmu Komunikasi jurusan Advertising pun menjadi lebih mengerti manfaat iklan, pemasaran, komunikasi, serta berbagai teori yang diajarkan selama perkuliahan dan penerapannya dalam kehidupan sehari-hari dalam berbagai bidang.

\section{Ucapan Terima Kasih}

Peneliti ingin mengucapkan terima kasih kepada Fakultas Ilmu Komunikasi Universitas Tarumanagara, narasumber, serta semua pihak yang turut membantu peneliti sehingga penelitian ini dapat diselesaikan. 


\section{Daftar Pustaka}

Badri Muhamad. (2011). Corperate and Marketing Communication. Jakarta: Universitas Mercu Buana.

BBC Indonesia (10 Desember 2020). Diakses dari https://www.bbc.com/indonesia/indonesia-49987127

Brogan, Chris. (2010). Social Media 101 Tactic and Tips to Develop Your Business Online. New Jersey, Canada: Wiley \& Son. Inc

Bungin, Burham. (2008:76). Penelitian Kualitatif: Komunikasi, Ekonomi, Kebijakan Publik dan Ilmu Sosial Lainnya. Jakarta: Kencana.

Kompas.com (10 Desember 2020). Diakses dari https://lifestyle.kompas.com/read/2019/10/22/194548020/depresi-dan-bunuh-di ri-di-indonesia-diprediksi-meningkat-mengapa?page $=\mathrm{al}$

Moleong, Lexy J. (2009). Metode Penelitian Kualitatif. Bandung: PT. Remaja Rosdakarya.

Mulyana, Deddy. (2001). Metodologi Penelitian Kualitatif Paradigma Baru Ilmu Komunikasi dan Ilmu Sosial Lainnya. Bandung: Remaja Rosdakarya.

Sugiyono. (2009:215). Metode Penelitian Kuantitatif, Kualitatif dan R\&D. Bandung: Alfabeta. 